\title{
O PRINCÍPIO DA PRECAUÇÃO E O PACOTE DO VENENO: O PROJETO DE LEI No 6.299/2002 E AS ESTRATÉGIAS PARA ENFRAQUECER A FISCALIZAÇÃO DOS AGROTÓXICOS NO BRASIL
}

\author{
Valmir César Pozzetti ${ }^{1}$ \\ Wagner Robério Barros Gomes ${ }^{2}$
}

RESUMO: O objetivo desta pesquisa foi o de contextualizar o surgimento dos agrotóxicos no âmbito mundial e a sua introdução no Brasil, identificando as principais mudanças trazidas pelo PL n ${ }^{0}$ 6.299/2002 sobre essas substâncias. A metodologia utilizada nesta pesquisa foi a do método dedutivo; quanto aos meios a pesquisa foi bibliográfica e quanto aos fins, qualitativa. Concluiu-se que o PL afronta o Princípio da Precaução por facilitar a liberação dos agrotóxicos, ignorando estudos científicos e a posição dos órgãos oficiais quanto aos reais danos irreversíveis destas substâncias para o meio ambiente e a saúde coletiva.

PALAVRAS-CHAVE: Agrotóxicos; Contaminação; Princípio da Precaução.

THE PRECAUTIONARY PRINCIPLE AND THE POISON PACKAGE: THE LAW PROJECT 6.299/2002 AND STRATEGIES TO WEAKEN THE INSPECTION OF PESTICIDES IN BRAZIL.

SUMMARY: The objective of this research was to contextualize the emergence of pesticides and its introduction in Brazil, identifying the main changes brought by pesticides Law Project $6.299 / 2002$ in brazilian law system. The methodology used in this research was the deductive method; the research was the bibliographical and as for the purposes, it was qualitative. It was concluded that Law Project violates the Precautionary Principle by facilitating the release of pesticides, ignoring scientific studies and the position of official Institutions that regarding the real irreversible damages of these substances to the environment and collective health.

KEYWORDS: Pesticides; Contamination; Precautionary Principle.

\footnotetext{
${ }^{1}$ Doutor em Biodireito/Direito Ambiental pela Université de Limoges/França. Professor Adjunto da Universidade Federal do Amazonas e Professor Adjunto da Universidade do Estado do Amazonas. E-mail: v_pozzetti@hotmail.com

${ }^{2}$ Mestrando do Programa de Mestrado em Direito Ambiental, da Universidade do Estado do Amazonas. E-mail: wagnner.gomess@gmail.com
} 


\section{INTRODUÇÃO}

Agrotóxicos, de um modo geral, são substâncias criadas pela indústria agroquímica para combater pragas na lavoura; sendo que, historicamente, algumas dessas substâncias são oriundas do processo de produção de armas químicas utilizadas durante as duas Grandes Guerras Mundiais. De forma sistemática, a introdução dessas substâncias no Brasil ocorreu em meados da década de 1960 com a implementação de uma política agrícola idealizada pelos Estados Unidos da América: A Revolução Verde. Paralelamente, ao longo dos anos, estudos têm demonstrando os riscos do uso irrestrito dessas substâncias.

Em 2015, a Associação Brasileira de Saúde Coletiva - ABRASCO produziu um Dossiê, alertando sobre os impactos negativos do uso indiscriminado dos agrotóxicos no país. Segundo a instituição, o Brasil é um dos maiores consumidores de agrotóxicos no mundo, e que dos 50 produtos mais utilizados em nosso país, 22 são proibidos na União Europeia. Outro estudo, Atlas: Geografia do uso Agrotóxicos no Brasil e Conexões com a União Europeia de 2017, ilustra que nos últimos anos esse consumo saltou de 170 mil toneladas para mais de 500 mil. Dessa forma, embora esse processo movimente uma economia com uma cifra alta, bilhões por ano; altos também são impactos negativos do uso dessas substâncias para o meio ambiente e saúde da coletividade.

Nesse contexto, no início deste ano, de forma incomum, um projeto de lei foi aprovado de forma célere em todas as comissões da Câmara Federal; estando prestes a ser apreciado pelo plenário da casa. Trata-se do Projeto de lei n 6.299/2002 de autoria do ex-senador Blairo Maggi que atualmente figura como Ministro da Agricultura. A este projeto ainda foram apensados outros 29 sobre a mesma temática: agrotóxicos; sendo assim, taxado de pacote do veneno. Ele tem por objetivo alterar a atual lei de Agrotóxicos vigente no país, a Lei $\mathrm{n}^{\circ} 7802 / 1989$, tornando mais fácil o processo de registro e liberação dessas substâncias, aumentando o poder político-econômico do Ministério da Agricultura nas decisões sobre certificação e uso de agrotóxicos no Brasil.

A problemática desta pesquisa é: em que moral ou ética se fundamenta um projeto de lei que ignora os estudos, as pesquisas e o clamor de órgãos oficiais e da sociedade civil organizada sobre os riscos do uso irrestrito de agrotóxicos? Tendo em vista que uma das alterações alavancadas pelo projeto de lei, e que mais preocupa, consiste no enfraquecimento da tríade regulatória que fiscaliza a entrada e uso dessas substâncias no país: Ministério do Meio Ambiente, Ministério da Saúde e Ministério da Agricultura. Com a mudança, haverá a unificação do processo de registro e liberação centralizado no comando do Ministério da Agricultura, mesmo que os órgãos dos Ministérios da Saúde e do Meio ambiente ainda possam 
emitir pareceres, há o risco de se transformarem em órgãos meramente consultivos, ou seja, tira-se o foco do meio ambiente e saúde, prevalecendo o foco preponderantemente econômico - ignorando o princípio da precaução.

O objetivo desta pesquisa é traçar um panorama do contexto do surgimento dos agrotóxicos no mundo e sua introdução no Brasil; identificando as principais mudanças trazidas pelo projeto de lei 6.299/2002 que enfraquece a fiscalização de agrotóxicos no país, sendo um contrassenso ao princípio da precaução.

A pesquisa se justifica, tendo em vista que o uso de agrotóxicos no Brasil avança a passos largos, e mesmo com estudos científicos advertindo para os impactos negativos dessas substâncias, a Câmara dos Deputados está prestes a votar um projeto de lei que tende a enfraquecer o processo de registro e liberação desses produtos no país. Dessa forma, é importante alertar sociedade quanto às incertezas cientificas frente a real potencialidade dos danos em curso, caso esse projeto de lei seja aprovado.

A metodologia utilizada nesta pesquisa foi o método dedutivo; quanto aos meios a pesquisa foi bibliográfica e quanto aos fins, qualitativa.

Dessa forma, o desenvolvimento deste trabalho está dividido em três momentos distintos, mas que se relacionam entre si. No primeiro momento, tem-se um breve contexto histórico-jurídico do surgimento dos agrotóxicos até sua introdução no Brasil. No segundo, trata-se da identificação das principais mudanças trazidas pelo projeto de lei $n^{\circ} 6.299 / 2002$. E por fim, o último engendra a análise que correlaciona às mudanças trazidas pelo projeto de lei frente ao princípio da precaução.

\section{BREVE CONTEXTO HISTÓRICO DO SURGIMENTO DO AGROTÓXICO E SUA INSERÇÃO NO CENÁRIO SOCIAL BRASILEIRO}

O conhecimento humano sobre substâncias químicas orgânicas e suas funcionalidades é tão antigo quanto sua utilização na arte de cultivar e nas estratégias de guerra, pois muitas destas substâncias foram utilizadas para esses fins. Lima (2016, p.10), exemplifica: "Em 200 a.C., Cato, em Roma, menciona o uso de betume (asfalto) para produção de inseticida. [...]”, e que: “[...] Em 600 a.C., os soldados do Rei grego Solon envenenaram córregos com raiz de Heléboro, visando provocar diarréia aos soldados inimigos, e assim os incapacitando para o combate [...].

Ao longo dos séculos, com o desenvolvimento científico, a humanidade passou a se aprofundar nos estudos das substâncias existentes na natureza e sua funcionalidade, a descobrir novas substâncias e a recriá-las, a adaptá-las e/ou alterá-las em laboratórios, como os 
organossintéticos (substâncias tóxicas artificiais de alta contaminação e baixa biodegradabilidade).

Assim, as substâncias que hoje conhecemos como agrotóxicos, foram se intensificando no final do século XIX e início do século XX, e conforme Souza (2018, p. 172) “[...] ocorre que, com o passar do tempo, sobretudo a partir da conjuntura histórica vivenciada a partir da Revolução Industrial e principalmente após a Segunda Guerra Mundial, houve uma intensificação extravagante do uso dos agrotóxicos [...]”,

Eventos de grande impactos. As substâncias ora eram usadas na lavoura, ora utilizadas na guerra - ou de formas interligadas. Contudo, o período das duas Grandes Guerras Mundiais merece destaque, pois foi nele que se verificou a internalização negativa do uso de substâncias tóxicas, desenvolvidas e empregadas como armas químicas contra seres humanos. Nesse sentido Lima (2016, p. 13) destaca que:

Juntamente com a busca pelo desenvolvimento de agrotóxicos a partir de compostos organossintéticos foi constatado a grande letalidade para o ser humano de alguns compostos até então sintetizados. Por essa razão, o extremo valor bélico verificado fomentou pesquisas e desenvolvimento das primeiras armas de guerra química altamente letais.

E Souza (2018, p. 174) destaca que a indústria química lucrou com esse processo.

[...] as indústrias produtoras acabaram descobrindo a capacidade letal desses venenos também em relação às pragas da agricultura e passaram a investir massivamente no desenvolvimento desses tipos de compostos com vistas a inseri-los cada vez mais no mercado agrícola.

Dessa forma, com o fim da II Guerra Mundial e a desestruturação social de vários países, era necessário recomeçar. Nesse contexto, para resolver a problemática da fome que assolava vários países e expandir o mercado norte-americano, era necessário mudar o modo de produção agrícola mundial. Saia-se da agricultura tradicional, restrita a pequenos produtores, para um processo de produção técnica em larga escala. A indústria química foi percebendo um novo mercado à vista, e começou a redirecionar a produção de armas químicas para a produção de agrotóxicos. A demanda sai de uma finalidade bélica, para fins agroeconômicos, endossado pelo discurso de erradicar a fome no mundo; contribuindo assim, com as bases para política agrícola norte-americana que se espalhou pelo mundo - a chamada Revolução Verde. 


\subsection{A Revolução Verde e a agrotoxicalização do Brasil}

Na década de 1960, o projeto capitalista norte-americano do desenvolvimento agrícola chega a diversos países com o objetivo de otimizar a produção agrícola; assim, as produções locais ou tradicionais foram transformadas produções com aparatos tecnológicos onde prevalecia a monocultura. Vaz (2006, p. 27) esclarece que o mundo estava diante da chamada Revolução Verde:

[...] baseada em uma política agrícola idealizada pelos EUA e difundida para os países pobres e em desenvolvimento, com o objetivo de possibilitar a abertura e a ampliação de mercados para os norte-americanos nos setores de sementes fertilizantes, agrotóxicos e máquinas agrícolas, proclamava o fim da fome no mundo.

A nova política, segundo Costa (2016, p. 06) teve “[...] forte fomento ao uso de agrotóxicos e demais insumos agrícolas promovido pela FAO, Organização das Nações Unidas para a Agricultura e Alimentação, e pelo Banco Mundial [...]”, instituições com atuação global que atuaram no campo político e financeiro para a difusão e implementação da Revolução Verde em diversos países. Assim, a indústria agroquímica foi avançando num mercado promissor para o uso de agrotóxicos.

O Brasil foi e ainda é um dos mercados promissores. Por aqui descreve Dunck (2016, p.226) “[...] uma série de políticas levada a cabo por diferentes governos cumpriu o papel de forçar a implementação da chamada modernização da agricultura, processo que resultou em altos custos sociais, ambientais e de saúde pública”.

Nesse contexto, em meados da década de 1960 esses produtos começaram sistematicamente adentrar no território brasileiro, o que, por conseguinte ensejou a necessidade de grandes áreas desmatadas para cultivos monocultores em larga escala, proliferando novas pragas na lavoura. Por conseguinte esclarece Andrades (2007, p. 50):

\footnotetext{
Para combater as que destroem as lavouras de monocultura, os produtores lançaram mão do uso intensivo de agrotóxicos - inseticidas, fungicidas químicos e herbicidas para eliminação de ervas indesejáveis conhecidas como ervas daninhas que crescem, rapidamente, no meio das plantações. Há de se registrar que, na medida em que se utilizam tais insumos para eliminação das pragas, as mesmas se tornam mais resistentes, demandando cada vez mais o uso de agrotóxicos.
}

Na década de 1970, “[...] a utilização de agrotóxicos ocorreu em larga escala no Brasil, especialmente no Sul, nas monoculturas de soja, milho e arroz [...]" (LUCCHESI, 2005, p. 5). 
O que se percebeu foi a criação de oligarquias agrícolas, a centralização de terras nas mãos de poucos. Para tanto, grandes áreas foram ocupadas, florestas irrestritamente desmatadas. Para que as girantes áreas de monocultura avançassem, e junto com elas o uso maciço de agrotóxicos.

Paralelo a esse processo, os Estados Unidos (idealizador da Revolução Verde), começaram a sentir as primeiras consequências do uso irrestrito de agrotóxicos. O DDT (Dicloro-Difenil-Tricloroetano) usado na lavou para combater pragas estava causando sérios problemas ambientais, ilustra Lima (2018, p. 11):

[...] começaram a suspeitar de que o poder residual do pesticida poderia ser o responsável por uma série de efeitos nocivos ao meio ambiente, aos animais e ao próprio homem. Tal suposição foi concebida tendo em vista o relato de diversos efeitos deletérios provocados pelo agrotóxico, ressaltando como informação a publicação do livro "Silent Spring" de Rachel Carson, em 1962, como um dos que obtiveram mais notoriedade. Neste livro, foi sugerido que o amplo uso do DDT poderia ser a principal causa da redução populacional de diversas aves; muitas delas seriam as de topo da cadeia alimentar como o falcão peregrino e a águia calva, animal símbolo do Estados Unidos.

O livro "Silent Spring", em português: "Primavera Silenciosa”, da bióloga e cientista norte-americana Rachel Carson, é considerado como marco histórico do surgimento ambientalista, uma obra grande repercussão. Pelas graves denúncias da autora sobre os efeitos nocivos dos agrotóxicos ao meio ambiente e a saúde das pessoas, os EUA proibiram o uso do DDT em 1970.

No final da década de 1970 e início da década de 1980, os movimentos ambientalistas chegaram ao Brasil e começam a influenciar as tomadas de decisão quanto às políticas ambientais no país. A preocupação com a poluição/degradação do meio ambiente, extinção de diversas espécies de animais e uso não sustentável dos recursos naturais, o seja, o desequilíbrio da biodiversidade provocado pela ação humana, vai gradativamente virando pauta política. E uso dos agrotóxicos de forma irrestrita começou a despertar preocupação.

No ordenamento pátrio, o termo agrotóxico foi empregado pela primeira vez na Constituição Federal de 1988:

Art. 220. A manifestação do pensamento, a criação, a expressão e a informação, sob qualquer forma, processo ou veículo não sofrerão qualquer restrição, observado o disposto nesta Constituição.

(...) omissis

$\S 4^{\circ}$ A propaganda comercial de tabaco, bebidas alcoólicas, agrotóxicos, medicamentos e terapias estará sujeita a restrições legais, nos termos do inciso II do parágrafo anterior, e conterá, sempre que necessário, advertência sobre os malefícios decorrentes de seu uso. (g.n.) 
Vê-se que foi uma vitória pequena, mas significativa para os movimentos socioambientais no Brasil, pois formalizava o termo agrotóxico, submetia a sua propagada a leis infraconstitucionais, com a tutela do direito à informação ao cidadão, determinando que as propagandas de agrotóxicos advertissem quanto aos malefícios desses produtos.

A grande mudança ocorreu em 1989, quando foi sancionada a Lei Federal $\mathrm{n}^{\circ}$ 7.802/1989 (regulamentada pelo Decreto no 4074/02), a Lei dos Agrotóxicos, que trata sobre a pesquisa, a experimentação, a produção, a embalagem e rotulagem, o transporte, o armazenamento, a comercialização, a propaganda comercial, a utilização, a importação, a exportação, o destino final dos resíduos e embalagens, o registro, a classificação, o controle, a inspeção e a fiscalização de agrotóxicos, seus componentes e afins, etc. Sobre a gênese infraconstitucional Souza (2018, p. 45) esclarece que:

\footnotetext{
A lei básica atual que disciplina os agrotóxicos no Brasil, Lei nº 7.802 de 1989, é produto de um cenário em que os efeitos ambientais e à saúde humana começaram a ser investigados pela ciência e sentidos pelos trabalhadores rurais, o que repercutiu em pressões da sociedade civil para uma disciplina mais rigorosa há muito adiada e justificada pela prevalência dos interesses das multinacionais fabricantes.
}

Um grande avanço, pois a Lei estabeleceu o registro prévio para a comercialização e uso desses produtos. E o mais importante, estabeleceu a tríade participativa dos ministérios: da Saúde, do Meio Ambiente e da Agricultura nos requisitos e diretrizes do que possa ser permitido.

No entanto, a indústria do agrotóxico se instalou durante esse período histórico e o agronegócio se estruturou, e hoje conta com representantes políticos no Congresso Nacional, a "bancada ruralista" que tenta de todas as formas revogar a Lei nº 7.802/1989.

\section{AS PRINCIPAIS MUDANÇAS NO DO PROJETO LEI 6.299/2002}

Desde o momento que a Lei dos Agrotóxicos, Lei Federal n. ${ }^{\circ} 7.802$ de 11 de julho de 1989 fora sancionada, o agronegócio por intermédio da bancada ruralista no Congresso Nacional vem buscando formas de enfraquecer e/ou revogar seus dispositivos, ou seja, Segundo Lucchesi (2005, p. 7) "Existe uma grande pressão da bancada ruralista no Congresso Nacional para instituir um registro facilitado dos agrotóxicos vindos de outros países [...]”, e com pouca ou nenhuma representatividade contrária, as tentativas nocivas começaram a dar resultados. 
Ao longo de quase 30 anos, desde a formalização da Lei dos Agrotóxicos em 1989, foram apresentadas dezenas de projetos de lei que buscavam seu enfraquecimento. Todos sem sucesso. Até que, no início deste ano, um projeto do Senado que estava em tramitação desde 2002 na Câmara dos deputados - o Projeto de Lei do Senado n. ${ }^{\circ}$ 6.299/2002 - teve seu processo acelerado e o cenário político atual no país nos deu indícios das negociações políticoeconômicas, conforme destaca um trecho da reportagem: Plataforma \#ChegaDeAgrotóxicos convoca sociedade a se mobilizar neste 2018, disponível no site da Associação Brasileira de Saúde Coletiva (ABRASCO, 2018):

\begin{abstract}
$\mathrm{O}$ ano se inicia com as manchetes de jornal denunciando os ruralistas vendendo seus votos favoráveis a Reforma da Previdência em troca da flexibilização da lei de agrotóxicos no Brasil e aprovação do Pacote do Veneno. No dia $1^{\circ}$ de fevereiro, o ministro da agricultura, Blairo Maggi se reuniu com a Monsanto, com a Anvisa e com a deputada Teresa Cristina, presidenta da comissão especial onde tramita o PL 6299, representante do Pacote do Veneno. Fica evidente para a população a quais interesses a produção de alimentos com agrotóxicos dessa maneira desmedida serve, às grandes transnacionais.
\end{abstract}

O fato é que a tramitação foi extremamente rápida; ou seja, em menos de 06 meses, o projeto de lei já está pronto para ser analisado pelo plenário da casa; o referido projeto de lei conseguiu apensar junto com ele outros 29 projetos de lei com matéria idêntica ou semelhante - daí o nome Pacote do Veneno.

O referido Projeto de Lei foi proposto inicialmente em 1999 por Blairo Maggi (o maior empresário do agronegócio da soja do país) quando Senador na época. Foi aprovado pelo Senado e encaminhado para Câmara dos Deputados. Atualmente, o Blairo Maggi é Senador afastado do exercício, pois ocupa atualmente o cargo de Ministro da Agricultura. Seu projeto de lei que chegou a Câmara dos Deputados em 2002 onde tramitava com a numeração PL n. ${ }^{\text {o }}$ 6.299 e cujo relator é o Dep. Nishimori (PR-PR) no início deste ano de 2018 teve seu tramite acelerado e em menos de 06 meses já está pronto para votação em plenário.

\title{
2.1. Principais mudanças
}

Das mudanças trazidas pelo Projeto de lei $n^{\circ}$ 6.299/2002, três delas merecem destaques: a mudança do termo agrotóxico, órgãos envolvidos nos registros, critério e prazos para a liberação. 


\subsubsection{A nomenclatura do termo}

O nome agrotóxico é uma criação brasileira para designar as substâncias toxicam usadas na lavoura e que acabam afetando o meio ambiente e a saúde das pessoas. Mas, não é o único empregado; antes da promulgação da Constituição Federal o termo era defensivos agrícolas. Analisar a questão é importante, pois a forma nominal com que esses produtos são apresentados à sociedade, permeia o imaginário coletivo. Peres (2003, p. 22) menciona que:

\footnotetext{
A legislação brasileira, até a Constituição de 1988 (publicada em 1989), tratava esse grupo de produtos químicos por defensivos agrícolas, denominação que, pelo seu próprio significado, excluía todos os agentes utilizados nas campanhas sanitárias urbanas $[\ldots]$
}

Após a Constituição Federal, o termo agrotóxico passou a ser empregado. A Lei Federal n. ${ }^{\circ} 7.802$ de 11 de julho de 1989 , em seu art. $2^{\circ}$, I, a, em sua parte introdutória estabelece que os agrotóxicos englobam: os produtos e os agentes de processos físicos, químicos ou biológicos. Um conceito bem abrangente e que abarca todas as substâncias tóxicas usadas na lavoura.

Sobre a questão do termo, no projeto do PL n ${ }^{\circ}$ 6.299/2002, o relator ao emitir seu voto pontuou no item décimo quarto que:

[...] conceito de "agrotóxico" utilizado pela atual Lei é inadequado tanto quanto o conceito de "defensivos agrícolas". Nas audiências públicas, alguns convidados defenderam a permanência da palavra "agrotóxico" e outros o termo "defensivos agrícolas" ou "produto fitossanitário"

No entanto, com a justificativa de ajustar o termo à literatura mundial, o que ficou decidido no relatório final é que a nomenclatura a ser empregada será: pesticidas. Em reportagem a BBC News Brasil intitulada: "Na contramão de Europa e EUA, Brasil caminha para liberar mais agrotóxicos", Larissa Bombardi, pesquisadora de renome na área, discorda da mudança do termo e destaca que não se trata de uma questão meramente semântica. Ela explicita que (BBC BRASIL NEWS, 2018):

É uma estratégia para mascarar o risco para a saúde humana que esses produtos têm. Quando você fala em pesticida, diminui a gama de significados. Os dois mais vendidos no Brasil são herbicidas, por exemplo, não pesticidas. Pesquisadores europeus já me disseram que era um ganho termos a expressão 'agrotóxico' na nossa lei, e que não deveríamos perder. 
Assim, seria um ponto negativo para o processo histórico dos movimentos socioambientais a mudança da nomenclatura que hoje é empregada no Brasil que bem reflete as características e finalidades dos produtos comercializados e utilizados.

\subsection{2. Órgãos responsáveis}

No tópico segundo, sobre os órgãos responsáveis pelo registro e liberação para o comércio e uso dos agrotóxicos no país, o projeto de lei também almeja essa alteração. Atualmente, A lei dos Agrotóxicos, Lei nº 7.802 de 1989 em seu art. $3^{\circ}$ estabelece que:

Art. $3^{\circ}$ Os agrotóxicos, seus componentes e afins, de acordo com definição do art. $2^{\circ}$ desta Lei, só poderão ser produzidos, exportados, importados, comercializados e utilizados, se previamente registrados em órgão federal, de acordo com as diretrizes e exigências dos órgãos federais responsáveis pelos setores da saúde, do meio ambiente e da agricultura.

Neste sentido, estabelece o Art. $5^{\circ}$ do Decreto $n^{\circ} 4.047 / 2002$ que regulamenta a lei dos agrotóxicos, lei $\mathrm{n}^{\mathrm{o}} 7.802 / 1989$, a competência dos órgãos federias envolvidos no processo de registro:

Art. 5 Cabe ao Ministério da Agricultura, Pecuária e Abastecimento:

I - avaliar a eficiência agronômica dos agrotóxicos e afins para uso nos setores de produção, armazenamento e beneficiamento de produtos agrícolas, nas florestas plantadas e nas pastagens;

(...) omissis

Art. 6ํㅡㄹ Cabe ao Ministério da Saúde:

(...) omissis

II - avaliar os agrotóxicos e afins destinados ao uso em ambientes urbanos, industriais, domiciliares, públicos ou coletivos, ao tratamento de água e ao uso em campanhas de saúde pública, quanto à eficiência do produto;

Art. 7o Cabe ao Ministério do Meio Ambiente:

(...) omissis

II - realizar a avaliação ambiental, dos agrotóxicos, seus componentes e afins, estabelecendo suas classificações quanto ao potencial de periculosidade ambiental;

O referido artigo autoriza que o registro seja feito pelos três órgãos, ou seja, um registro baseado numa tríade institucional, o processo tramita em paralelo nos três órgãos. Esse procedimento registral para $\operatorname{Vaz}(2006$, p. 62) “[...] tem caráter eminentemente público, é imposto como medida de segurança social e individual nas esferas de alimentação saúde e meio ambiente [...]"; evitando os impactos negativos advindos de um processo facilitado.

O Projeto de Lei ${ }^{\circ}$ 6.299/2002, porém, visa alterar essa regra. Haverá a unificação do processo registro e liberação que ficará sob o comando do Ministério da Agricultura cujo atual 
ministro é o autor do projeto e um dos maiores empresários do agronegócio no país. Os três órgãos continuaram a emitir pareceres sobre o produto, no entanto, com a Centralização no Ministério da Agricultura, o Ministério da Saúde por intermédio da ANVISA e o Ministério do Meio Ambiente por intermédio do IBAMA correm o risco de desempenhar papeis apenas de órgãos consultivos.

No texto da relatoria do projeto de lei na Câmara dos Deputados, a justificativa seria o excesso de burocracia e longo tempo para que os produtos fossem registrados e liberados. Como as pragas nas lavouras estão ficando resistentes aos atuais agrotóxicos, esses impasses estariam dificultando a entrada de novos produtos - fazendo com que os agricultores reutilizassem cada vez mais os produtos atualmente permitidos.

Há um questionamento de que as pesquisas investigativas não acompanham o tempo de demanda do mercado; no entanto, o tempo de demanda do mercado também compromete os resultados satisfatórios das pesquisas investigativas; ou seja, a forma como a agroindústria vem utilizando os agrotóxicos, sempre demandará de mais produtos em curtos espaços de tempo, nesse sentido, esclarece Brainbate (2012, p. 12):

\footnotetext{
Apesar de existir no mercado um grande número de compostos para controlar as mais diversas pragas daninhas, insetos, fungos e outros organismos, existe uma demanda crescente por novos produtos, uma vez que os organismos desenvolvem resistência a tais compostos após certo tempo de contato. Com isso, estes passam a ser menos efetivos e, muitas vezes, perdem totalmente a atividade. Outro aspecto importante a considerar é o surgimento frequente de novos insetos-pragas, plantas daninhas e fungos, havendo a necessidade do estudo de novos produtos para controlar tais organismos.
}

Assim, compreende-se que a alteração do registro e liberação dos atuais e novos produtos agrotóxicos mediante a centralização dessa responsabilidade exclusivamente pelo Ministério da Agricultura está mais relacionada com um interesse de víeis político-econômico do agronegócio do que qualquer outra justificativa razoável. O sistema de produção e consumo é crescente e chegou num ritmo em que as demandas de mercado consideram inaceitável aguardar o resultado de pesquisas de longa data que lhes diga que tal produto é ou não para o ambiente e saúde da coletividade. De outra forma, a questão burocrática em si não deve ser argumento para uma liberação facilitada de produtos cujas substâncias têm impactos negativos no meio ambiente. 


\title{
2.1.3. Prazos e Critérios de avaliação
}

Atualmente, acerca da questão técnico-científica para a liberação de novos agrotóxicos

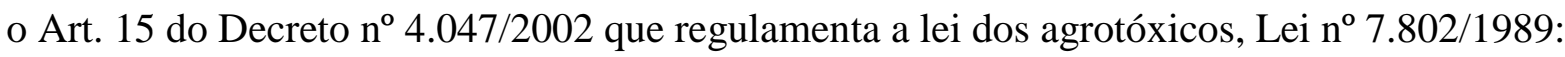

\begin{abstract}
Art. 15. Os órgãos federais competentes deverão realizar a avaliação técnicocientífica, para fins de registro ou reavaliação de registro, no prazo de até cento e vinte dias, contados a partir da data do respectivo protocolo.

$\S 1$ 1 A contagem do prazo será suspensa caso qualquer dos órgãos avaliadores solicite por escrito e fundamentadamente, documentos ou informações adicionais, reiniciando a partir do atendimento da exigência, acrescidos trinta dias.

$\S 2^{\underline{o}}$ A falta de atendimento a pedidos complementares no prazo de trinta dias implicará o arquivamento do processo e indeferimento do pleito pelo órgão encarregado do registro, salvo se apresentada, formalmente, justificativa técnica considerada procedente pelo órgão solicitante, que poderá conceder prazo adicional, seguido, obrigatoriamente, de comunicação aos demais órgãos para as providências cabíveis.
\end{abstract}

Logo, ao contrário do que é justificado no Projeto de Lei, de que a demora liberação compromete o desenvolvimento da atividade agrícola, há convir conforme o respaldo legal acima que se o produto a ser liberado apresentar alto grau de toxidade e/ou periculosidade, os efeitos de uma liberação precoce e sem resultados contundentes pode causar danos maiores.

No entanto, o Projeto de Lei, altera a norma atual e estabelece diversos prazos que vão de 30 dias a 24 meses. (p. 44-45) e cria o instituto do registro especial temporário, concedido num prazo de 30 dias para os agrotóxicos que sejam permitidos em pelo menos 03 países integrantes da Organização para Cooperação do desenvolvimento Econômico OCDE. Um parâmetro irregular, pois, essa organização é composta por países desenvolvidos e em desenvolvimento, ou seja, uns são mais restritivos e outros não quanto ao uso de agrotóxicos.

Quanto à proibição de agrotóxicos dispõe o Art. $2^{\circ}$, II, $\S 6^{\circ}$ da atual lei dos agrotóxicos, lei $\mathrm{n}^{\mathrm{o}} 7.802 / 1989$ estabelece que:

Art. $2^{\circ}$ Para os efeitos desta Lei, consideram-se:

(...) omissis

II - componentes: os princípios ativos, os produtos técnicos, suas matérias-primas, os ingredientes inertes e aditivos usados na fabricação de agrotóxicos e afins.

(...) omissis

$\S 6^{\circ}$ Fica proibido o registro de agrotóxicos, seus componentes e afins:

a) para os quais o Brasil não disponha de métodos para desativação de seus componentes, de modo a impedir que os seus resíduos remanescentes provoquem riscos ao meio ambiente e à saúde pública;

b) para os quais não haja antídoto ou tratamento eficaz no Brasil;

c) que revelem características teratogênicas, carcinogênicas ou mutagênicas, de acordo com os resultados atualizados de experiências da comunidade científica;

d) que provoquem distúrbios hormonais, danos ao aparelho reprodutor, de acordo com procedimentos e experiências atualizadas na comunidade científica; 
e) que se revelem mais perigosos para o homem do que os testes de laboratório, com animais, tenham podido demonstrar, segundo critérios técnicos e científicos atualizados;

f) cujas características causem danos ao meio ambiente.

Por conseguinte, a análise dos critérios para o registro está no Decreto no 4.074/2002 que regulamenta a lei $\mathrm{n}^{\mathrm{o}} 7.802 / 1989$ :

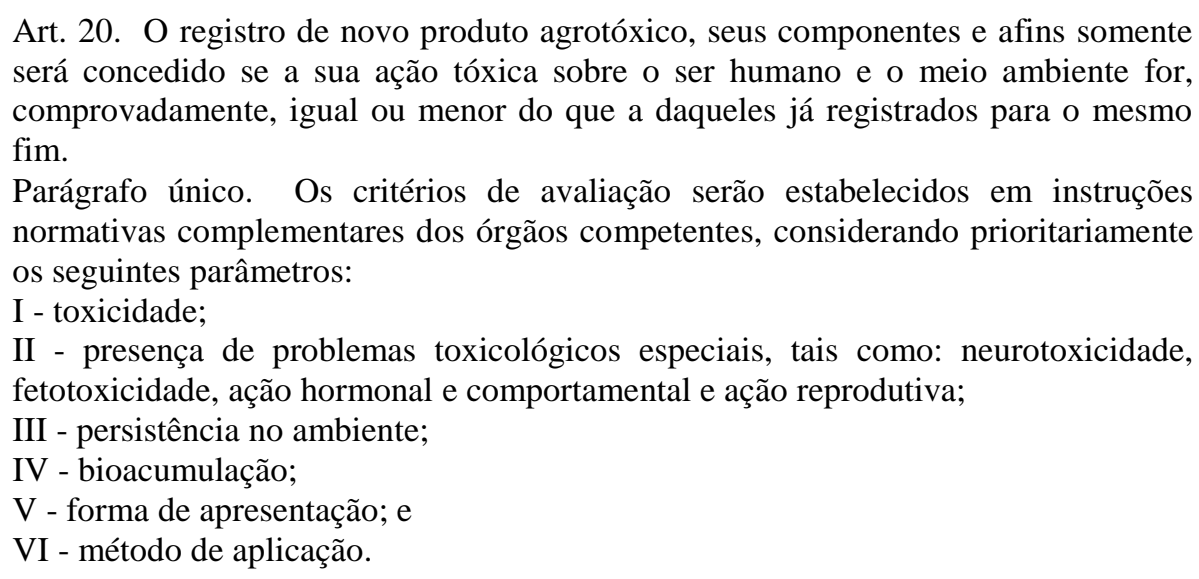

Como se verifica, os atuais critérios levam em consideração o grau de toxidade e periculosidade dos agrotóxicos. O Projeto de Lei $n^{\circ}$ 6.299/2002 elimina essas restrições, substituindo-as apenas pelo critério: risco inaceitável; um risco segundo o respectivo Projeto de Lei em seu art. $2^{\circ}$, VI, f), considerado como: “insatisfatório por permanecer inseguro ao ser humano ou ao meio ambiente, mesmo com a implementação das medidas de gerenciamento dos riscos." (p 37-38) - um certo contrassenso quanto ao princípio da precaução que preconiza a não utilização de qualquer substancia se houver incerteza cientifica quanto aos riscos.

E se há um contrassenso quanto a um princípio fundamental do ornamento jurídico, como o da precaução, isto segue em oposição ao que determina o art. 225 da Constituição Federal de 1988 que determinar que: "Todos têm direito ao meio ambiente ecologicamente equilibrado, bem de uso comum do povo e essencial à sadia qualidade de vida, impondo-se ao Poder Público e à coletividade o dever de defendê-lo e preservá-lo para as presentes e futuras gerações".

Estudos como o da Associação Brasileira de Saúde Coletiva (ABRASCO) de 2015 e o Geografia: Uso de Agrotóxicos no Brasil e Conexões com a União Europeia, de Larissa Bombardi, USP 2017 alertam para o alto índice de contaminação de alimentos, do ambiente, de pessoas - consequência da escalada cada vez maior do uso irrestrita de agrotóxicos no Brasil. 


\title{
3. O PRINCÍPIO DA PRECAUÇÃO E O PROJETO LEI No 7802/1989
}

A palavra princípio designa início, começo, origem, ponto de partida. Assim, princípio, como fundamento de Direito, têm como utilidade permitir a aferição de validade das leis, auxiliar na interpretação das normas e integrar lacunas.

Nesse sentido Pozzetti e Monteverde (2017, p. 200) destacam que:

\begin{abstract}
Princípios são regras fundantes, que antecedem a norma jurídica, são a base, a estrutura da própria norma, uma vez que traduzem os anseios da sociedade que lhe originou, no sentido do justo, do honesto, do correto e do que deve ser cumprido pela sociedade. Os objetivos do Direito Ambiental é estabelecer regras cogentes, de maneira a prevenir danos futuros. Neste sentido, o direito ambiental atua no campo educativo, preventivo e não no âmbito reparador. As regras são postas no sentido de que as ações sejam tomadas antes que o dano se consolide.
\end{abstract}

Em 1992, ocorreu na cidade do Rio de Janeiro uma grande Conferência Internacional Mundial - A Conferência das Nações Unidas sobre o Meio Ambiente e Desenvolvimento que reuniu diversos países do planeta, preocupados com as questões ambientais e a destruição acelerada do meio ambiente, também conhecida como Declaração do Rio/92 ou ECO/92.

Dessa Convenção resultou uma carta de princípios que passariam a orientar a conduta dos países signatários da mesma. Dentre eles encontra-se o Princípio da Precaução, que é considerado um princípio fundamental do direito internacional no que tange a preservação do meio ambiente. Neste sentido, Vaz (2006, p. 97) explica que o referido princípio [...] assentase sobre dois pressupostos principais: a tendência natural de as atividades humanas causarem dano ao meio ambiente e a incerteza cientifica acerca dessa potencialidade e dos efeitos que dela decorrerão.

Vejamos o que diz a Declaração do Rio/92 sobre Meio Ambiente e Desenvolvimento Sustentável:

Princípio 15. Com o fim de proteger o meio ambiente, o princípio da precaução deverá ser amplamente observado pelos Estados, de acordo com suas capacidades. Quando houver ameaça de danos graves ou irreversíveis, a ausência de certeza científica absoluta não será utilizada como razão para o adiamento de medidas economicamente viáveis para prevenir a degradação ambiental.

A Declaração tem um viés de compromisso ético entre os países que dela participaram, e o princípio da precaução, desde então, tem sido utilizado amplamente pela doutrina e por legisladores como um parâmetro para obstar atividades quais inexistam certezas científicas. 
Vaz (2006, p. 97) afirma que: "Em matéria ambiental, prevenir é mais importante do que reconstituir e obter indenização futura por dano já ocorrido”. E, Pozzetti (2014, p.107) adverte que: "Se o Princípio da Precaução fosse universalmente aplicado, muitas substâncias tóxicas, contaminantes e práticas negligentes nem seriam produzidas ou usadas”. Ou seja, na maioria dos casos, os danos ambientais tendem a se irreparáveis.

O projeto de lei $\mathrm{n}^{\circ}$ 6.299/2002, pelas medidas que adota, se aprovado, facilitará o registro, a liberação, o comércio e o uso dos agrotóxicos no Brasil - pois, segundo seus defensores, o atual processo é burocrático e o tempo que os órgãos reesposáveis por estudos técnico-científicos levam para emitir parecer favorável ou não é demasiadamente longo frente ao tempo mercadológico. Contudo, salienta Pozzetti, "Para se aplicar efetivamente o Princípio da Precaução temos que suplantar a pressa, a precipitação, a improvisação, a rapidez insensata e a vontade de resultado imediato".

A segurança ambiental e a saúde coletiva de uma nação não podem estar submissas a um processo mercadológico cujo valor moral da atividade se paute apenas pelo lucro, sem se preocupar com os resultados nocivos advindos desse processo. A Constituição Federal de 1988 em seu Art. 196 determina que "A saúde é direito de todos e dever do Estado, garantido mediante políticas sociais e econômicas que visem à redução do risco de doença e de outros agravos [...]”. Também, na Carta Magna tem-se a determinação quanto ao meio ambiente no “Art. 225 Todos têm direito ao meio ambiente ecologicamente equilibrado, bem de uso comum do povo e essencial à sadia qualidade de vida, impondo-se ao Poder Público e à coletividade o dever de defendê-lo e preservá-lo para as presentes e futuras gerações.” No entanto, com esse Projeto de Lei o que se verifica é um contrassenso constitucional por parte da Casa Legislativa.

Diversas entidades oficiais e da sociedade civil organizada se posicionaram contrárias ao projeto de lei $\mathrm{n}^{\text {o }}$ 6.299/2002. Em reportagem divulgada pela Câmara Notícias, setor de comunicação da Câmara dos Deputados, intitulada: "Ibama, Fiocruz, Idec e outras entidades se manifestam contra mudança na lei de agrotóxicos" (2018), a referida matéria destaca que: "Em audiência pública na Comissão de Desenvolvimento Urbano da Câmara, entidades dizem que efeitos dos pesticidas incluem contaminação de alimentos, da água e do ar e relacionam uso desses produtos a problemas de saúde”

Uma delas, a Fundação Oswaldo Cruz - Fiocruz, do Ministério da Saúde emitiu Nota Técnica que pontua diversos tópicos negativos do projeto de lei. Como exemplo, um novo instituto do registro e autorização provisória de agrotóxicos, disposto no art. $3^{\circ}, \S 6^{\circ}$ ao $10^{\circ}$, do projeto de lei $n^{\circ} 6.299 / 2002$, explicita a Nota Técnica (2018, p. 11): 
Esta proposição representa uma ameaça de dano ao ambiente e a saúde humana, violando o princípio da precaução ao evitar a adoção de medidas precaucionarias, mesmo diante de incertezas no que diz respeito aos eventuais efeitos das substâncias químicas sobre os seres e os ambientes. Mediante a ameaça de danos graves ou irreversíveis, o princípio da precaução deve ser sempre considerado no processo de tomada de decisões na proteção da saúde humana e ambiental, reforçando as responsabilidades éticas do processo regulatório de produtos perigosos.

Outros exemplos no projeto de lei em que o princípio da precaução foi desconsiderado estão: no art. $2^{\circ}$, inciso XX, que explica a mistura em tanque como: "associação de produtos fitossanitários, de produtos de controle ambiental e afins no tanque do equipamento aplicador". Aqui menciona Folgado (p.04):

[...] atualmente, ainda que recorrentes, não são permitidas a realização de caldas/misturas de agrotóxicos, porém o texto atual permite esse tipo de prática. 0 grande problema é que a mistura de determinadas composições químicas pode resultar em novas formulações que não foram testadas pelos órgãos reguladores. Assim é possível que estejamos ainda mais expostos a altos graus de toxidade não identificados [...]

Outro exemplo citado por Folgado (p. 10), referente às reanalises previstas no art. 29 do projeto de lei destaque que:

Art. 29. As reanálises dos produtos fitossanitários e afins deverão ser realizadas e concluídas pelo órgão federal responsável pelo setor da agricultura no prazo de até 1 (um) ano, prorrogável mediante justificativa técnica por 6 (seis) meses, sem prejuízo da análise de pleitos e alterações de registro em tramitação, bem como da manutenção da comercialização, produção, importação e uso do produto à base do ingrediente ativo em reanalise. [mais uma violação do princípio da precaução, pois mesmo que existam indícios de que o produto cause algum dano, a ponto de o colocar em reanálise, o produto será mantido no mercado. Em se constatando, danos neurotóxicos, por exemplo, tal produto terá sido mantido. Trata-se de mais um absurdo que coloca em risco a saúde pública e o meio ambiente em detrimento dos interesses econômicos das empresas],

Assim, o projeto de lei $\mathrm{n}^{\circ}$ 6.299/2002 se moldou como uma possível norma revogadora da atual legislação vigente, a Lei Federal no 7.802/1989. Um projeto com víeis meramente político-econômico, descartando as possíveis consequências dos danos irreversíveis que o uso irrestrito dessas substâncias podem causar ao meio ambiente e a saúde coletiva do país. 


\section{CONSIDERAÇÕES FINAIS}

As substâncias químicas que hoje conhecemos como agrotóxicos tiveram seu ápice de produção durante da Revolução Industrial e o período das duas Grandes Guerras Mundiais. Foram introduzidas no Brasil por volta da década de 1960 com a política norte-americana da Revolução Verde que incentivou a expansão das indústrias agroquímicas no mundo. A partir desse contexto, movimentos socioambientais, instituições sociais e a sociedade civil organizada vêm mostrando as consequências negativas do uso irrestrito dessa substância para o meio ambiente e a saúde humana. Em oposição, o setor do agronegócio se fortaleceu e estabeleceu representatividade no Congresso Nacional onde buscam legitimar suas ações mercantis. Neste ano, projeto de lei n ${ }^{\circ} 6.299 / 2002$, com tramitação célere, está prestes a ser aprovado o que fará com que mais agrotóxicos sejam utilizados irrestritamente no Brasil.

A problemática desta pesquisa foi a dúvida acerca de que moral ou ética se fundamentou projeto de lei no 6.299/2002 que visa enfraquecer a fiscalização dos agrotóxicos no país, desconsiderando os estudos, as pesquisas e o clamor de órgãos oficiais e da sociedade civil organizada sobre os riscos do uso irrestrito dessas substâncias.

Estabeleceu-se como objetivo a importância de traçar um panorama do contexto do surgimento dos agrotóxicos no mundo e sua introdução no Brasil; identificando as principais mudanças trazidas pelo projeto de Lei $n^{\circ}$ 6.299/2002 que visa enfraquecer a fiscalização de agrotóxicos no país e um contrassenso ao princípio da precaução.

A pesquisa nos permitiu concluir que a política de desenvolvimento rural iniciada com o Advento da Revolução Verde criou uma oligarquia agrícola no país que hoje é identificada como agronegócio cujo mercado movimenta bilhões por ano, determinando suas regras de mercado. Assim, percebe que o projeto de Lei ${ }^{\circ}$ 6.299/2002 é fruto da moral mercantilista deste setor agrário cujo foco é aumentar cada vez mais seus lucros anuais; ignorando valores éticos quais se comprometem com a o uso sustentável e/ou proteção do meio ambiente e os cuidados com a saúde da coletividade, dentre eles, o princípio da precaução que correlaciona medidas economicamente viáveis para prevenir a degradação ambiente diante de danos irreversíveis. 


\section{REFERÊNCIAS}

ABRASCO - Associação Brasileira de saúde coletiva. Plataforma \#ChegaDeAgrotóxicos convoca sociedade a se mobilizar neste 2018. 19 fev. 2018. Disponível em: < https://www.abrasco.org.br/site/outras-noticias/ecologia-e-meio-ambiente/plataformaagrotoxicos-sociedade/33219/>. Consultado em: 05 ago. 2018.

ANDRADES, Thiago Oliveira de; GANIMI, Rosângela Nasser. Revolução verde e a apropriação capitalista. CES Revista. V. 21, 2007. Disponível em: <https://www.cesjf.br/revistas/cesrevista/edicoes/2007/revolucao_verde.pdf>. Consultado em: 25 jul.2018.

BOMBARDI, Larissa Mies. Geografia do uso de agrotóxicos no Brasil e conexões com a União Europeia. São Paulo: USP, 2017. Disponível em: < https://https://www.larissabombardi.blog.br/atlas2017 >. Consultado em: 15 jul.2018.

BRAIBANTE, Mara Elisa Fortes; ZAPPE, Janessa Aline. A química dos agrotóxicos. Química Nova na Escola, v. 34, n. 1, p. 10-15, 2012. Disponível em:< http://qnesc.sbq.org.br/online/qnesc34_1/03-QS-02-11.pdf >. Consultado em: 25 jul.2018.

BBC NEWS BRASIL. Na contramão de Europa e EUA, Brasil caminha para liberar mais agrotóxicos. 27 jun. 2018. Disponível em: <https://www.bbc.com/portuguese/brasil44621328>. Consultado em: 05 ago. 2018.

BRASIL. Constituição da República Federativa do Brasil de 1988. Congresso Nacional. Brasília, DF, out. $1988 . \quad$ Disponível em: <http://www.planalto.gov.br/ccivil_03/constituicao/constituicaocompilado.htm>. Consultada em: 10 ago. 2018.

BRASIL. Decreto $\mathbf{n}^{\mathbf{0}} 4.07$ de 04 de janeiro de 2002. Regulamenta a Lei no 7.802 , de 11 de julho de 1989, que dispõe sobre a pesquisa, a experimentação, a produção, a embalagem e rotulagem, o transporte, o armazenamento, a comercialização, a propaganda comercial, a utilização, a importação, a exportação, o destino final dos resíduos e embalagens, o registro, a classificação, o controle, a inspeção e a fiscalização de agrotóxicos, seus componentes e afins, e dá outras providências.. Congresso Nacional. Brasília, DF, 04 jan. 2002. Disponível em: < http://www.planalto.gov.br/cciViL_03/decreto/2002/D4074.htm>. Consultado em: 10 ago. 2018.

BRASIL. FIOCRUZ. Nota Técnica de 14 de maio de 2018. Análise do Projeto de Lei ${ }^{\circ}$ 6.299/2002. Disponível em: <https://portal.fiocruz.br/sites/portal.fiocruz.br/files/documentos/nota_tecnica_pl_agratoxicos. pdf >. Consultada em: 21 ago. 2018.

BRASIL. Lei $\mathbf{n}^{\mathbf{0}} \mathbf{7 . 8 0 2}$, de 11 de julho de 1989. Dispõe sobre a pesquisa, a experimentação, a produção, a embalagem e rotulagem, o transporte, o armazenamento, a comercialização, a propaganda comercial, a utilização, a importação, a exportação, o destino final dos resíduos e embalagens, o registro, a classificação, o controle, a inspeção e a fiscalização de agrotóxicos, seus componentes e afins, e dá outras providências.. Congresso Nacional. Brasília, DF, 11 jul.

Rev. de Direito Agrário e Agroambiental | e-ISSN: 2526-0081 | Porto Alegre | v. 4 | n. 2 | p. 71 - 90 | Jul/Dez. 2018 
1989. Disponível em: <http://www.planalto.gov.br/ ccivil_03/LEIS/L7802.htm>. Consultada em: 10 ago. 2018.

CÂMARA NOTÍCIAS. Ibama, Fiocruz, Idec e outras entidades se manifestam contra mudança na lei de agrotóxicos. 23 jun. 2018. Disponível em: $<$ http://www2.camara.leg.br/camaranoticias/noticias/ AGROPECUARIA/557911-IBAMA,FIOCRUZ,-IDEC-E-OUTRAS-ENTIDADES-SE-MANIFESTAM-CONTRA -MUDANCANA-LEI-DE-AGROTOXICOS.html >. Consultado em: 05 ago. 2018.

CÂMARA DOS DEPUTADOS. Projeto de Lei $\mathbf{n}^{\mathbf{0}} \mathbf{6 . 2 9 9}$ de 2002. Altera os arts $3^{\circ}$ e $9^{\circ}$ da Lei $n^{\circ} 7.802$, de 11 de julho de 1989, que dispõe sobre a pesquisa, a experimentação, a produção, a embalagem e rotulagem, o transporte, o armazenamento, a comercialização, a propaganda comercial, a utilização, a importação, a exportação, o destino final dos resíduos e embalagens, o registro, a classificação, o controle, a inspeção e a fiscalização de agrotóxicos, seus componentes e afins, e dá outras providências. Disponível em: <http://www.camara.gov.br/proposicoesWeb/prop_mostrarintegra?codteor=1654426\&file name=Tramitacao-PL+6299/2002 >. Consultado 20 ago. 2018

COSTA, Letícia Fancelli; PIRES, Gabriel Lino de Paula. Análise Histórica sobre a Agricultura e o Advento do Uso de Agrotóxicos no Brasil. ETIC - Encontro de Iniciação Científica - issn 21-76-8498, v. 12, n. 12, 2016. Disponível em: <http://intertemas.toledoprudente.edu.br/index.php/ETIC/article/viewFile/5433/5164>.

Consultado em: 23 jul.2018.

DUNCK, Ellen Adeliane Fernandes Magni. Agrotóxicos e a Intervenção do Capital na Agricultura. Revista de Direito Agrário e Agroambiental, v. 1, n. 1, p. 221-237, 2015. Disponível em: <http://www. indexlaw.org/index.php/rdaa/article/view/328>. Consultado em: 24 jul.2018.

FOLGADO, Cleber Adriano Rodrigues. Breves Considerações sobre os Projetos de Lei contidos no Processo de Desmonte da Legislação de Agrotóxicos. 10 mai. 2018. Disponível em: <http://aba-agroecologia.org.br/ wordpress/wp-content/uploads/2018/05/Parecer-Pacotedo-Veneno-10-de-maio-de-2018.pdf>. Consultado em: 24 ago.2018.

LUCCHESI, Geraldo. Agrotóxicos: construção da legislação. Brasília: Câmara dos Deputados, 2005. Disponível em: <http://www2.camara.leg.br/a-camara/documentos-epesquisa/estudos-e-notas-tecnicas/areas-da-conle/tema19/2005_13187.pdf >. Consultado em: 26 jul.2018.

LIMA, Keila dos Santos Cople et al. Agrotóxicos: Presença Diária nos Alimentos Consumidos. Semioses, v. 10, n. 1, p. 9-22, 2016. Disponível em: $<$ http://apl.unisuam.edu.br/revistas/ index.php/Semioses/article/ view/1981996X.2016v10n1p9>. Consultado em: 20 jul.2018.

PERES, Frederico; MOREIRA, Josino Costa; DUBOIS, Gaetan Serge. Agrotóxicos, saúde e ambiente: uma introdução ao tema. É veneno ou é remédio, p. 21-41, 2003. Disponível em: $<$ https://portal.fiocruz.br/sites/

portal.fiocruz.br/files/documentos/cap_01_veneno_ou_remedio.pdf $>$. Consultado em: 15 jul.2018. 
POZZETTI, Valmir César. Alimentos Transgênicos e o Direito do Consumidor à Informação. Revista Jurídica, v. 3, n. 36, p. 103-131, 2014. Disponível em: <http://revista.unicuritiba.edu.br/index. php/ RevJur/article/view/993>. Consultado em: 20 ago.2018.

POZZETTI, Valmir Cesar; MONTEVERDE, Jorge Fernando Sampaio. Gerenciamento Ambiental e Descarte do Lixo Hospitalar. Veredas do Direito: Direito Ambiental e Desenvolvimento Sustentável, v. 14, n. 28, p. 195-220, 2017. Disponível em: <http://www.domhelder.edu.br/revista/index.php/veredas/article/view/949>. Consultado em: 15 ago.2018.

SOUZA, Larissa Camapum de. Análise da Legislação sobre Agrotóxicos no Brasil: Regulação ou Desregulação do Controle do Uso?. Revista Jurídica da Escola Superior do Ministério Público de São Paulo, v. 11, n. 1, 2018. Disponível em: < http://www.esmp.sp.gov.br/revista_esmp/index.php/RJESMPSP/article/view/ 329>. Consultado em: 22 jul.2018.

SOUZA, Larissa Camapum de; BELAIDI, Rabah. Agrotóxicos e Biodiversidade: Terminologia, Causas e Impactos. Revista de Direito Agrário e Agroambiental, v. 2, n. 1, p. 168-187, 2016. Disponível em: < http://www.indexlaw.org/index.php/rdaa/article/view/585>. Consultado em: 24 jul.2018.

VAZ, Paulo Afonso Brum. O Direito Ambiental e os agrotóxicos: responsabilidade civil, penal e administrativa. Porto alegre: Livraria do Advogado, 2006. 